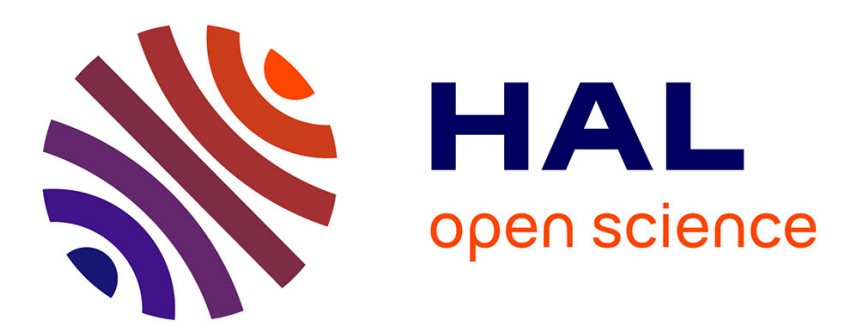

\title{
The effect of the orientation and the height of periodic sub-micrometric texturing on dropwise condensation
}

Nicolas Pionnier, Julie Vera, Elise Contraires, Stéphane Benayoun, Rémi Berger, Stéphane Valette

\section{- To cite this version:}

Nicolas Pionnier, Julie Vera, Elise Contraires, Stéphane Benayoun, Rémi Berger, et al.. The effect of the orientation and the height of periodic sub-micrometric texturing on dropwise condensation. Journal of Colloid and Interface Science, 2018, 10.1016/j.jcis.2018.04.043 . hal-02938754

\section{HAL Id: hal-02938754 https://hal.science/hal-02938754}

Submitted on 22 Sep 2020

HAL is a multi-disciplinary open access archive for the deposit and dissemination of scientific research documents, whether they are published or not. The documents may come from teaching and research institutions in France or abroad, or from public or private research centers.
L'archive ouverte pluridisciplinaire HAL, est destinée au dépôt et à la diffusion de documents scientifiques de niveau recherche, publiés ou non, émanant des établissements d'enseignement et de recherche français ou étrangers, des laboratoires publics ou privés. 


\section{Droplet images (droplets in white)}

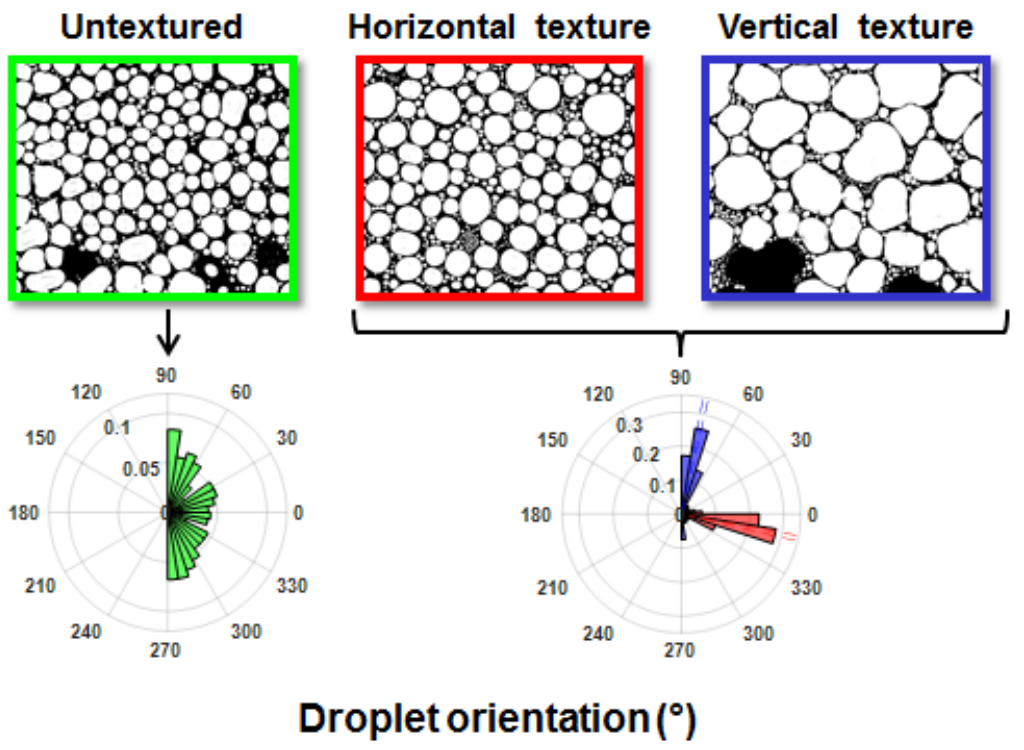




\title{
The effect of the orientation and the height of periodic sub-micrometric texturing on dropwise condensation
}

\author{
Nicolas Pionnier ${ }^{\mathrm{a}, 1, *}$, Julie Vera $^{\mathrm{a}}$, Elise Contraires $^{\mathrm{a}}$, Stéphane Benayoun ${ }^{\mathrm{a}}$, \\ Rémi Berger ${ }^{\mathrm{b}}$, Stéphane Valette $\mathrm{a}^{\mathrm{a}, 2, * *}$ \\ ${ }^{a}$ Université de Lyon, Ecole Centrale de Lyon, Laboratoire de Tribologie et Dynamique des \\ Systèmes, UMR 5513,F-69131, Ecully, France \\ ${ }^{b}$ PSA Peugeot Citroën, E78943 Vélizy-Villacoublay, France
}

\begin{abstract}
Controlling condensation conditions by surface topography is of prime interest. The aim of this work is to investigate the behavior of water droplets condensing on oriented sub-micrometric structures representing ripples with wavelengths around $800 \mathrm{~nm}$.

Droplet behavior was studied on different ripples heights and on untextured surfaces. It was specifically looked at how the presence of ripples creates geometrical confinement, and how that influences the deformation and the orientation of single droplets. Results show that the condensed droplets follow the orientation of textured features, especially with high structures height $(150 \mathrm{~nm})$. This is shown by the decreasing of droplet roundness with ripples height. The relative number of circular droplets (roundness near to 1) is around 0.6 for $70 \mathrm{~nm}$ high ripples and decrease to around 0.2 for $150 \mathrm{~nm}$ high ripples. The corresponding relative number on untextured surface is around 0.5.

A mechanism, based on droplets pinning and hysteresis, is proposed to explain the influence of the ripples orientation in a vertical plane, onto the droplet deformation during coalescence step.

Finally, the presence of ripples is shown to barely impact breath figure dynamics. Number of droplets and mean droplet radius for the textured and untextured surfaces present a comparable evolution.
\end{abstract}

Keywords: Dropwise condensation, Oriented structures, Ripples, Wettability, Polycarbonate

\footnotetext{
${ }^{*}$ Corresponding author

${ }^{* *}$ Principal corresponding author

Email addresses: nicolas.pionnier@doctorant.ec-lyon.fr (Nicolas Pionnier), stephane.valette@ec-lyon.fr (Stéphane Valette )

${ }^{1}$ Phone: +33 (0)4 72186248

${ }^{2}$ Phone: $+33(0) 472186438$
} 


\section{Introduction}

The development of surface texturing techniques over the last 20 years has significantly advanced our understanding of surface wetting properties. $\mathrm{Nu}-$ merous studies have shown that the direction of a given surface pattern influences the orientation of sessile droplets by forming anisotropic droplets, oriented droplets or even self-propelled droplets $[1,2,3,4,5,6,7,8]$. Oriented structures favor droplet deformation and in effect, create anisotropic wetting as opposed to isotropic wetting [9]. Parallel microgrooves oriented perpendicular to gravity influenced water droplet motion and enhanced water drainage [10, 11, 12]. On both hydrophilic and hydrophobic surfaces, water droplet sliding coincided with lower droplet volume and a lower tilt angle caused droplets to roll off of the surface $[13,10,14]$.

Textured surfaces can also affect the nucleation and growth of droplets during the condensation process. Condensation patterns, also known as breath figures, can effectively be modified by the presence of chemical or geometrical patterns on the substrate [15]. Macner et al. [16] studied how chemical gradients impact condensation patterns. Due to this gradient, the droplet size distribution becomes more monodisperse and shift to the smaller radius. Hydrophilic patches on hydrophobic surfaces have also been studied for how they impact breath figures $[17,18]$.

Inspired by examples occurring in nature and helped further by important developments in texturing technology, surface geometrical patterns have been designed specifically to control water condensation and water harvesting. Medici and coworkers have shown that geometrical patterns favor droplet growth at the edges and not the interior $[19,20]$.

Breath figures and droplet growth rates during the condensation process are relevant in the context of a number of applications, notably for water harvesting in desert areas, for heat transfer processes and for the formation of dew on transparent surfaces $[21,22,23,24]$. The impact of dew on transparency can be problematic when it impacts the efficacy of helmet visors, diving masks or car headlights where the light emission is affected by the presence of dew. Modifying breath figures using surface patterning presents a viable and promising solution by slowing droplet growth rates and reducing droplet flow. The main concern involved with adding a geometric pattern relates to the pattern size. Surface patterns need to be smaller than visible wavelengths to prevent any negative effects on visibility.

A surface texture pattern is not visible to the naked eye if its feature size is below $200 \mathrm{~nm}$ [25]. Our study presents the lowest dimensions pattern we managed to create, which in this case, had a wavelength around $800 \mathrm{~nm}$. Texturing in this case was thereby rendered visible, but only generated a slight haze or iridescence. We structured our study around observations of the behavior of large droplets by considering surface texture size (the smallest observed droplets measured $6.7 \mu \mathrm{m} \pm 0.2 \mu \mathrm{m}$ in diameter and were approximately 9 times larger than the corresponding textured pattern). This underlined for us the importance of determining to what degree these structures impact large droplets. 
To date, only a handful of investigations has focused on surface textures at the nanoscopic scale in the context of modifying breath figures. One such study published by Quere et al. describes submicrometric patterns they developed to facilitate antifogging, which they showed are more effective when the textured patterns are conical instead of cylindrical [26]. Even fewer studies have explored how specific submicrometric patterning affects breath figure orientation.

Our main objective in the present work was to investigate the impact of oriented submicrometric patterns, also known as Laser-Induced Periodic Surface Structures (LIPPS) [27, 28], on the orientation of nanodroplets in volume during the condensation process. The LIPPS, or ripples, were produced on transparent polycarbonate, which is a thermoplastic polymer widely used for headlights. We placed smooth and textured polycarbonate in an environmental chamber where temperature and humidity were controlled. Our custom designed setup allowed us to pay particular attention to the droplets geometry and its impact on the dynamics of condensation described through tracking the number of droplets and corresponding growth rates.

\section{Experimental setup and methods}

\subsection{Condensation setup and process}

A customized experimental setup was developed for the specific purpose of condensation tracking. A schematic view is shown in figure 1. A more detailed description of the experimental setup and its calibration was given in a previous article [29]. This device consisted of a box measuring $10 \times 10 \times 10 \mathrm{~cm}^{3}$ and assimilated to a relative humidity and temperature controlled chamber where samples could be fixed on a cooling plate. The objective was to decrease local temperature of the samples to below dew point (as condensation begins with cooling below this temperature). Controlling the air temperature and relative humidity inside the box allowed to set the dew point, and the cooling plate ensured that the temperature of sample surfaces remained below this temperature.

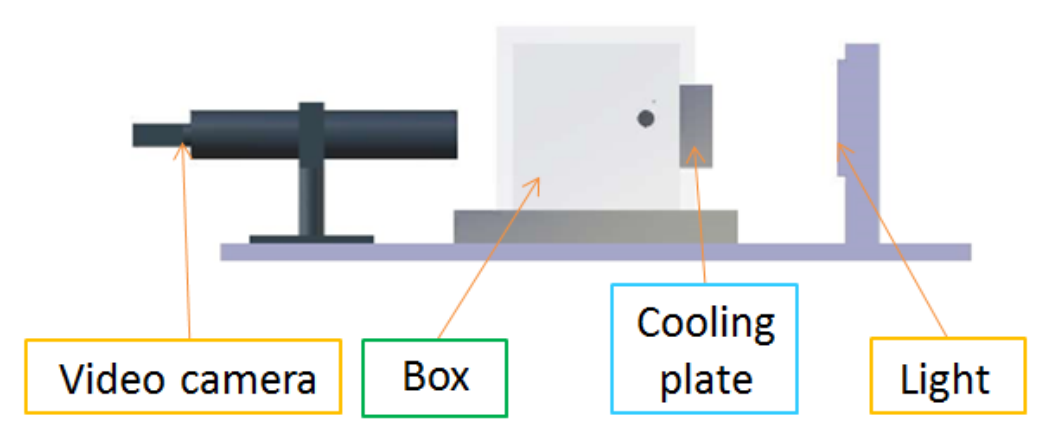

Figure 1: Schematic view of the experimental setup. 
Two 150 watt heat cartridges placed on the underside of the box heated the air temperature inside by convection. The box temperature was measured with a $1 \mathrm{~mm}$ diameter $\mathrm{K}$ type thermocouple placed at $15 \mathrm{~mm}$ from the cold surface. This thermocouple position was chosen to avoid measurements of the decreasing temperature due to the cold surface. The measured values were calculated with a proportional-integral-derivative control loop (Eurotherm 3216 PID Controller) driving the operating temperature of the cartridges, which in turn controlled the interior temperature.

Once the box's interior temperature was stabilized, the relative humidity could then be regulated or adjusted. A second PID loop was added to control a proportional flow valve to mix in a controlled proportion water-saturated air with an almost dry air in order to reach a desired relative humidity level inside of the box. This RH level was measured using a Vaisala HMP110 hygrometer placed at $15 \mathrm{~mm}$ from the cold surface. Before being mixed, the air was filtered with a $0.01 \mu \mathrm{m}$ gas filter.

To decrease the sample-holder temperature, we used two $23.4 \mathrm{~W}$ thermoelectric coolers (UEPT-1RE-063-050M125S, UWE Electronic) piloted with a Eurotherm 3216 and coupled with thermal grease (MX-4, Arctic). The temperature was measured with another $1 \mathrm{~mm}$ diameter $\mathrm{K}$ type thermocouple placed inside the sample-holder. The substrate temperature was thus not directly measured. We then built an abacus to obtain the precise temperature of this surface. This abacus was formed with a linear equation of $-\mathrm{T}_{\mathrm{S}}=\mathrm{A} \cdot \mathrm{T}_{\mathrm{sh}}+\mathrm{B}$ with $\mathrm{T}_{\mathrm{S}} /{ }^{\circ} \mathrm{C}$ for the surface temperature at the observation point, and $\mathrm{T}_{\mathrm{sh}} /{ }^{\circ} \mathrm{C}$ for the sampleholder temperature. Three separate tests were conducted to measure the A and $\mathrm{B}$ coefficients. The measured values were given in a previous article [29].

Droplet formation on the sample surfaces was observed at normal incidence with a digital 5 megapixel grayscale video camera. The transparency of the samples combined with a hole drilled into the cooling plate allowed to illuminate them from behind. The resulting spatial resolution of this system ranged from $0.28 \mu \mathrm{m} /$ pixel $\pm 0.03 \mu \mathrm{m} /$ pixel to $2.60 \mu \mathrm{m} /$ pixel $\pm 0.08 \mu \mathrm{m} /$ pixel. Post-processing of these raw images was conducted with a MATLAB computational program, customized for droplet detection.

For the experimental tests, we set the flow rate of humid air entering the box to $1.15 \mathrm{~L} / \mathrm{min}$. The pressure inside the box was at ambient level (box not airtight), with gas temperature and relative humidity set respectively at $30{ }^{\circ} \mathrm{C} \pm 2.5$ ${ }^{\circ} \mathrm{C}$ and $45 \% \pm 1.6 \%$. The subcooling temperature was measured at roughly 1 ${ }^{\circ} \mathrm{C}$. The given experimental values are stabilized during the whole duration of each test. Image acquisition was performed at $1 \mathrm{~Hz}$ with a spatial resolution of $1.34 \mu \mathrm{m} /$ pixel $\pm 0.04 \mu \mathrm{m} /$ pixel. The observed area measured approximately $3.3 \times 2.7 \mathrm{~mm}^{2}$ and the smallest droplet detected was 5 pixels $(=6.7 \mu \mathrm{m} \pm 0.2 \mu \mathrm{m})$ in diameter.

\subsection{Samples characterization and preparation}

The polycarbonate textured surfaces were obtained by injection molding using Makrolon 24588 from Bayer [30]. Using this technique does not add a production step in the fabrication process as would, for example, applying a 
chemical coating. The process is to create a mold which is textured from which individual polycarbonate parts are then replicated. The substrates used in this study were replications of a laser machined mold using a $1030 \mathrm{~nm}$ wavelength Satsuma laser from Amplitude Systèmes. This laser was configured to reach $400 \mathrm{fs}$ impulsions of $1.5 \mathrm{~W}$ at a rate of $250 \mathrm{kHz}$. It was used to irradiate the surface with five successive impulsions and a $10 \mu \mathrm{m}$ pace to create laser-induced periodic surface structure (LIPPS) or ripples [31].

Varying the injection molding parameters permitted to control the replication process and to obtain different replication rates, and consequently, allowed to produce LIPPS with various heights on the polycarbonate surfaces. Three heights were studied corresponding to replication rates of around $25 \%, 50 \%$ and $75 \%$.

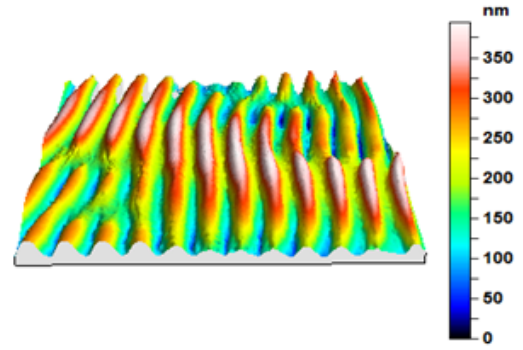

(a)

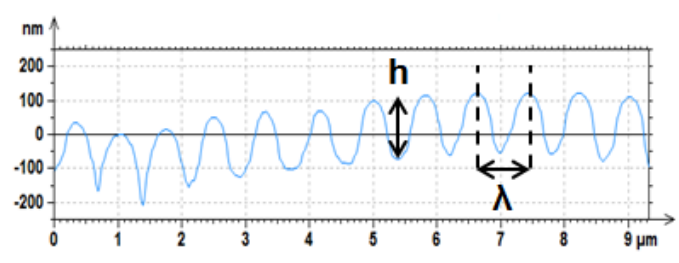

(b)

Figure 2: (a) AFM scan (size: $10 \times 10 \mu \mathrm{m}^{2}$ ) of ripples replicated at $75 \%$ on polycarbonate. (b) A corresponding height profile of the AFM scan presented in (a).

We compared these three surfaces to an untextured surface, also made by injection molding but by using a mirror polish mold.

These surfaces were analyzed by atomic force microscopy AFM (NanoscopeV NanoMan Bruker Corporation). Four $10 \times 10 \mu^{2}$ scans were taken at different locations on each surface. As shown in figure 2, the LIPPS shaped the surfaces with ripple wavelengths of $\langle\lambda\rangle=760 \mathrm{~nm} \pm 14 \mathrm{~nm}$ (mean value taken from the four scans of each textured sample). The features height $h$ and the roughness parameters $\mathrm{S}_{\mathrm{q}}$ and $\mathrm{S}_{\mathrm{a}}$ for the three surfaces named 1,2 and 3 are provided in table 1. For a statistical approach, the height was measured on 15 features of each scan. The same analysis was conducted for the untextured surface. The obtained roughness parameters $\mathrm{S}_{\mathrm{q}}$ and $\mathrm{S}_{\mathrm{a}}$ are also included in table 1 .

Wetting properties of each surface were characterized by static contact angle and hysteresis measurements. Five $1 \mu \mathrm{l}$ sessile drops were deposited on the surfaces for the different analyses. The hysteresis was measured by injecting water into the droplet and by evaporation. We chose to use $1 \mu \mathrm{l}$ drops as this corresponded to droplet size obtained during the condensation tests. These experiments were performed using a Kruss DSA30 tensiometer. Results are provided in table 1 and in figure 3 in which the contact angle hysteresis of the three samples are plotted. As ripples are oriented structures, wetting analysis 


\begin{tabular}{|c|c|c|c|c|c|c|c|c|}
\hline & Sample & $\mathrm{S}_{\mathrm{q}}(\mathrm{nm})$ & $\mathrm{S}_{\mathrm{a}}(\mathrm{nm})$ & $\begin{array}{c}\text { Features } \\
\text { height }(\mathrm{nm})\end{array}$ & $\begin{array}{c}\text { Contact } \\
\text { angle } \theta\left({ }^{\circ}\right)\end{array}$ & $\begin{array}{l}\text { Advancing } \\
\text { angle } \theta_{a}\left({ }^{\circ}\right)\end{array}$ & $\begin{array}{l}\text { Receding } \\
\text { angle } \theta_{\mathrm{r}}\left({ }^{\circ}\right)\end{array}$ & $\begin{array}{c}\text { Hysteresis } \\
\Delta \theta\left({ }^{\circ}\right)\end{array}$ \\
\hline \multirow{3}{*}{ Parallel } & 1 & $68.5 \pm 6.6$ & $59.0 \pm 4.2$ & $154 \pm 19$ & $97 \pm 1$ & $98 \pm 2$ & $52 \pm 11$ & $46 \pm 13$ \\
\hline & 2 & $51.4 \pm 11.2$ & $42.0 \pm 8.4$ & $108 \pm 15$ & $98 \pm 2$ & $96 \pm 1$ & $52 \pm 5$ & $44 \pm 6$ \\
\hline & 3 & $44.1 \pm 11.8$ & $35.8 \pm 10.0$ & $70 \pm 14$ & $99 \pm 2$ & $102 \pm 2$ & $64 \pm 5$ & $38 \pm 6$ \\
\hline \multirow{4}{*}{ Perpendicular } & 1 & $68.5 \pm 6.6$ & $59.0 \pm 4.2$ & $154 \pm 19$ & $93 \pm 1$ & $101 \pm 5$ & $70 \pm 3$ & $31 \pm 7$ \\
\hline & 2 & $51.4 \pm 11.2$ & $42.0 \pm 8.4$ & $108 \pm 15$ & $98 \pm 1$ & $101 \pm 2$ & $68 \pm 2$ & $34 \pm 4$ \\
\hline & 3 & $44.1 \pm 11.8$ & $35.8 \pm 10.0$ & $70 \pm 14$ & $92 \pm 7$ & $93 \pm 2$ & $69 \pm 6$ & $25 \pm 8$ \\
\hline & Untextured & $7.3 \pm 2.1$ & $5.6 \pm 1.9$ & & $95 \pm 2$ & $101 \pm 2$ & $68 \pm 2$ & $33 \pm 4$ \\
\hline
\end{tabular}

Table 1: Table of the surface parameters of the three textured samples - 1,2 and 3 - and of the untextured surface.

was conducted for two ripples orientations - one with ripples parallel to the observation direction and the second with ripples perpendicular to the observation direction.

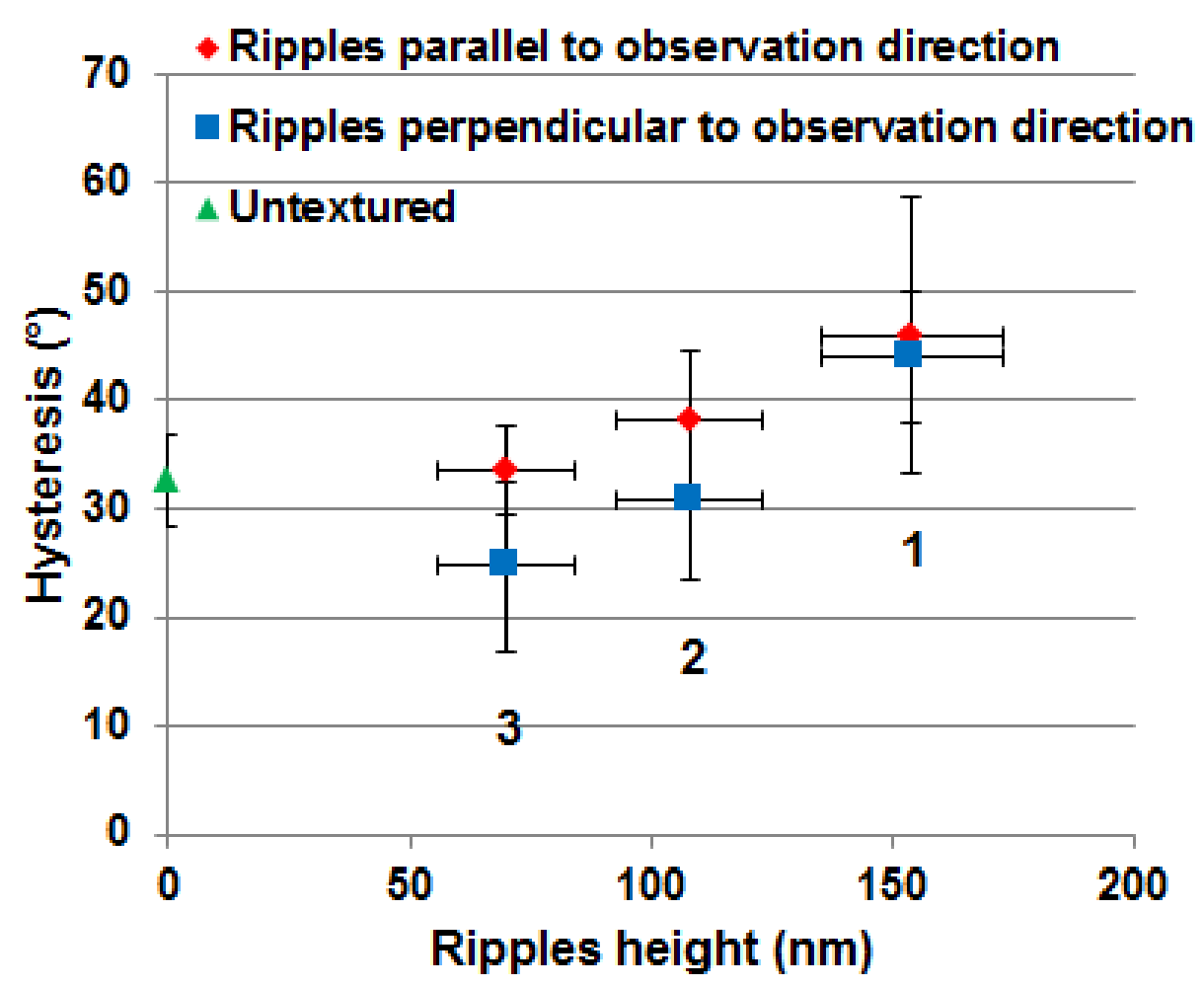

Figure 3: Plot of the contact angle hysteresis of the three textured samples - 1, 2 and 3 - and of the untextured surface. 
Before conducting the condensation tests, the samples were cleaned following the protocol described below:

1. $70 \%$ ethanol $/ 30 \%$ distilled water was used to remove grease without degrading the polycarbonate (polycarbonate becomes less stable in contact with ethanol solutions of $95 \%$ or greater concentration) [32],

2 . the ethanol was removed completely with distilled water before each sample was placed for 15 minutes in a distilled water ultrasound bath to remove dust,

3. the samples were placed in an oven heated to $120{ }^{\circ} \mathrm{C}$ for six hours to remove any water on the surface and absorbed by the polymer.

\section{Results and discussion}

\subsection{Droplets deformation and orientation}

For the three ripple structure heights and the untextured surface, we recorded the droplets deformation and orientation at a fixed time (1 h26 min) as illustrated in figure 4 . We selected this specific time when droplets were most clearly visible. A second figure in Supporting Information, figure S1, shows time evolution (with four different times) of sample 1 (highest ripple height) together with the untextured surface. In these two figures, droplet deformation is depicted in black and white images (the background is represented in black and droplets in white). The degree of deformation shown in these figures is quantified by the roundness calculated with $\left((4 \pi \cdot\right.$ droplet area $) /$ droplet perimeter $\left.^{2}\right)$ and by the orientation given by polar plots in which the length of each bar represents the relative number of observations. This relative number is the number of droplets positioned in the given orientation divided by the number of all the droplets. The orientation corresponds to the angle between the major axis of the droplet (represented by an ellipse) and horizontal positioning shown as being only between $-90^{\circ}\left(270^{\circ}\right)$ and $90^{\circ}$. On these polar plots, the ripples orientation is also illustrated with two dashed lines representing the dispersion of five distinct orientation measurements.

\subsubsection{Droplets deformation and surface coverage}

As results show, the presence of ripples can effectively induce droplets deformation which can be seen in the images and the droplets roundness graphs shown in figure 4 . Droplets deformation in response to micrometric-scale structures has previously been studied by drop deposition [13, 33, 10, 9, 34]. A more recent study investigated micro-scale droplets deposited on nanometer patterns [35]. However, while we would expect droplet deposition by condensation to modify the deformation process and, contrary to the literature, the droplets we studied were relatively large compared to the corresponding sub-micrometric structures.

Results showed that high ripples height of a textured surface enhance droplets deformation. The most pronounced deformation we observed was for sample 1 , while the lowest occurred for sample 3. By analyzing the sequence of images, 
we can see that the droplet deformations are due to inhibited relaxation following droplet coalescence. Coalescence is the process by which several droplets merge to form a single larger droplet [36]. This new droplet is characterized by an elongated shape which eventually becomes hemispherical. The return to a spherical cap formation is referred to as relaxation. To recover a hemispherical shape, the large axis decreases and the small axis increases. During this process of relaxation, a restoring linear force applies on the contact line. This restoring force $f$ (per unit length) can be approximated by considering the central axis of a just coalesced droplet [37]:

$$
\mathrm{f}=\sigma\left(\cos (\vartheta)-\cos \left(\vartheta_{\mathrm{r}}\right)\right)
$$

with $\sigma$ representing the surface tension. $\vartheta$ is the time dependent contact angle along the large axis and $\vartheta_{\mathrm{r}}$ the receding angle. At $\mathrm{t}=0$, just after the droplets fusion, $\vartheta$ is the lowest. When relaxation occurs, $\vartheta$ increases and the restoring force decreases. Once the relaxation is complete, $\vartheta$ will equal $\vartheta_{\mathrm{r}}$. Therefore, to initiate the relaxation and the contact line motion, $\vartheta$ must be lower than $\vartheta_{\mathrm{r}}$. A low value of $\vartheta_{\mathrm{r}}$ increases the amplitude of droplet deformation because it limits droplets relaxation. This theory is consistent with the observations and measurements presented in table 1 . Indeed, $\vartheta_{\mathrm{r}}$ is shown decreasing relative to the height of the ripples.

Another approach to evaluating droplet relaxation amplitude is to estimate the resisting force $\mathrm{f}_{\mathrm{r}}$, by determining the threshold of contact line motion [38]. This force measured by length unit is due to hysteresis and can be used to characterize a surface. It is given for a spherical cap by [39, 40]:

$$
\mathrm{f}_{\mathrm{r}}=\sigma\left(\cos \left(\vartheta_{\mathrm{r}}\right)-\cos \left(\vartheta_{\mathrm{a}}\right)\right)
$$

As shown in table 1, as the height of ripples structures increases, $\vartheta_{\mathrm{r}}$ decreases which reduces relaxation and increases hysteresis. This in turn augments the resisting force. Thereby, the relaxation is less effective and droplet deformation is more pronounced. More importantly, if $\mathrm{f}_{\mathrm{r}}$ is very high, the resulting droplet deformation creates a liquid film. It is this very surface that eliminates fogging [41].

The ripples orientation also influences the hysteresis and thus the droplets deformation.

During condensation test, the samples were fixed to a vertical cooling soleplate. The droplets were thus positioned on a support inclined at $90^{\circ}$ and this inclination, similar to ripples orientation, affected the droplet deformation. The nature of the deformation of a sample whose ripples are oriented in the gravity direction will differ from a sample with ripples with perpendicular orientation. In the inclination direction, the top and bottom angles of droplets (see figure 5) leaned respectively toward the receding and advancing angles. However, for 


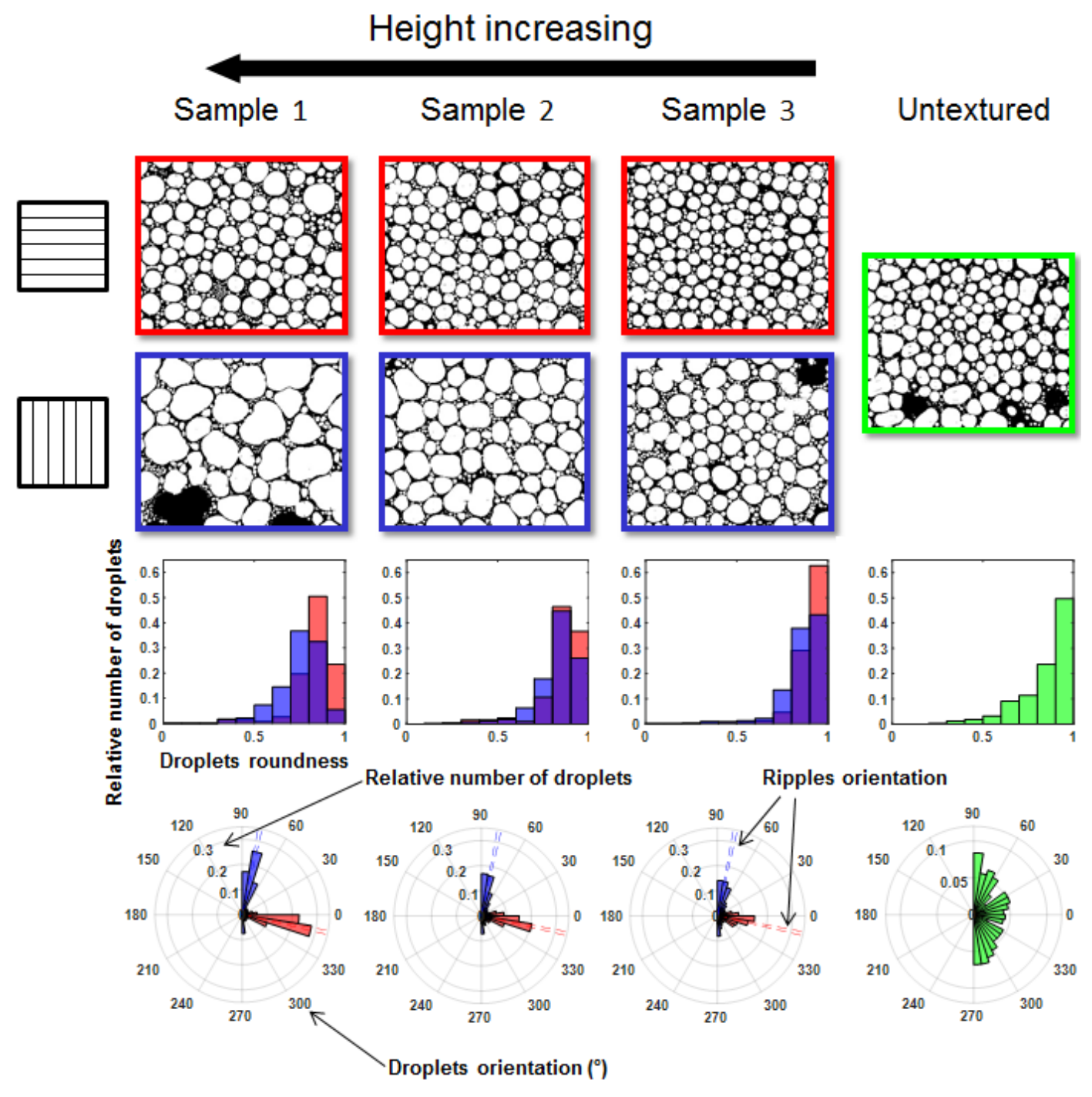

Figure 4: Study of the deformation and orientation of the droplets of the three textured samples and of the untextured surface. This study corresponds to the analysis of pictures taken at the same time (about $1 \mathrm{~h} 26 \mathrm{~min}$ ). The figure is comprised of black and white images (with white droplets) and shows corresponding droplets roundness and orientation. The roundness and the orientation are defined in the text. The color blue shows results obtained for ripples with parallel orientation to gravity, and red shows results for ripples with perpendicular orientation to gravity.

the angles on droplets sides (right and left), the inclination had no effect. As a function of their orientation just after coalescence, the droplets exhibited, during their relaxation, either receding or advancing displacements in the gravity 
direction. We explain the droplet relaxation in these two displacement configurations shown in figure 5 by providing two proposed mechanisms - one droplet elongated vertically and the other elongated horizontally. In the case of vertically elongated droplet, the support inclination aided the droplet reach the receding angle at the top while limiting the possibility of obtaining the same angle at the bottom of the droplet. Similarly, for the horizontally elongated droplet, the inclination helped obtain the advancing angle at the bottom of the droplet and limited the same change at the top of the droplet.

Describing the impact of inclination brings us next to examine the effect of ripples orientation. We understand that when ripples were positioned perpendicular to the force of gravity, droplet relaxation movements along the grooves of the ripples were not reduced by either the inclination of the support or by the presence of ripples. This corresponds to "no pinning" in the perpendicular ripples case of figure 5. On the contrary, limitations to movement as a result of ripples occurred mainly when ripples were in the perpendicular direction. This generates the "pinning" and "low pinning" situations described in the perpendicular ripples case of figure 5. The term "low pinning" is used to emphasize the balance between the pinning force due to ripples presence and the increased droplet mobility due to support inclination. With the help of the hysteresis influenced by inclination in the perpendicular ripples direction and possible freedom of movement in the other direction, we understand that droplets relaxation could occur quite effectively. When the ripples were set vertically, however, horizontal droplet relaxation was logically hampered by the ripples, and vertical relaxation was similarly affected by the inclining support effect on hysteresis. This creates the pinning conditions presented for parallel ripples figure 5. In short, droplets deformation on vertical ripples was exacerbated.

The process of droplet deformation is also accompanied by spreading. The absence of the relaxation process does not cause coalesced droplets to decrease their contact area with the surface substrate, which subsequently impacts the surface coverage $\varepsilon$. Figure 6 shows the surface coverage of the three textured samples oriented with ripples perpendicular and parallel to the direction of gravity. The surface coverage of the untextured surface is also included here as a reference surface. Two steep decreases of the surface coverage of ripples 1 (parallel) are observed at the end of the acquisition. These decreases are frenquently observed and could be due to big coalescence events that clean a part of the observed surface decreasing $\varepsilon$ or droplet detection errors. As shown in figure 6 , the maximum $\varepsilon$ value of each sample did not reach a plateau of $55 \%$, as expected for smooth surfaces and hemispherical droplets, due to the hysteresis $[20,42]$. Moreover, the maximum surface coverage increased with the height of the ripples. The orientation of the ripples had also an effect - the highest $\varepsilon$ were obtained for samples 1 and 2 with ripples positioned toward the direction of gravity. These two surfaces had the highest ripple heights and their ripples orientation had the highest blocking effect on droplets relaxation. Relaxation on these two surfaces was thus significantly limited, which consequently provoked the highest degree of droplet spreading. 


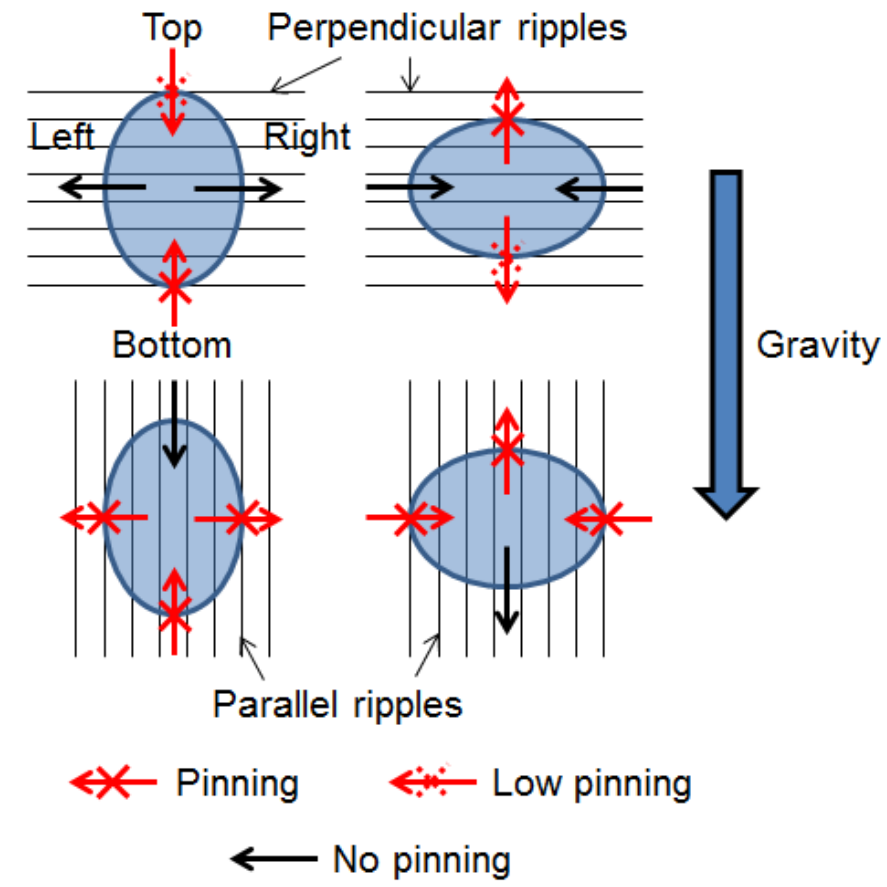

Figure 5: Diagram showing a proposed mechanism that could explain the droplet relaxation on samples textured with ripples and fixed on a vertical support. Two droplet orientations are represented on ripples positioned parallel and perpendicular to the direction of gravity. The black arrows represent the direction of free motion, the red crossed arrows represent the pinning direction of a triple line, and the red dot crossed arrow shows pinning direction where the movement can be allowed with the inclination of the support.

\subsubsection{Droplet orientation}

Our results showed that droplets of water on untextured surfaces form hemispherical shapes. The isotropic nature of the surface induces no preferential deformation. Uniformly oriented droplets are shown in the images and polar plots of figure 4 .

The ripples themselves are anisotropic structures with a preferential direction. Droplets condensed on this kind of texture are oriented in the direction of the ripples, as shown in figure 4. A large number of the droplets on this surface were elongated in shape matching ripples positioned in the same direction. Interestingly, the number of these elongated droplets increased with the height of the ripples. This orientation behavior, however, should be qualified. The roundness and orientation of droplets were often only slightly pronounced. Droplets exhibiting weak deformation, consequently, showed only slight orientation. 


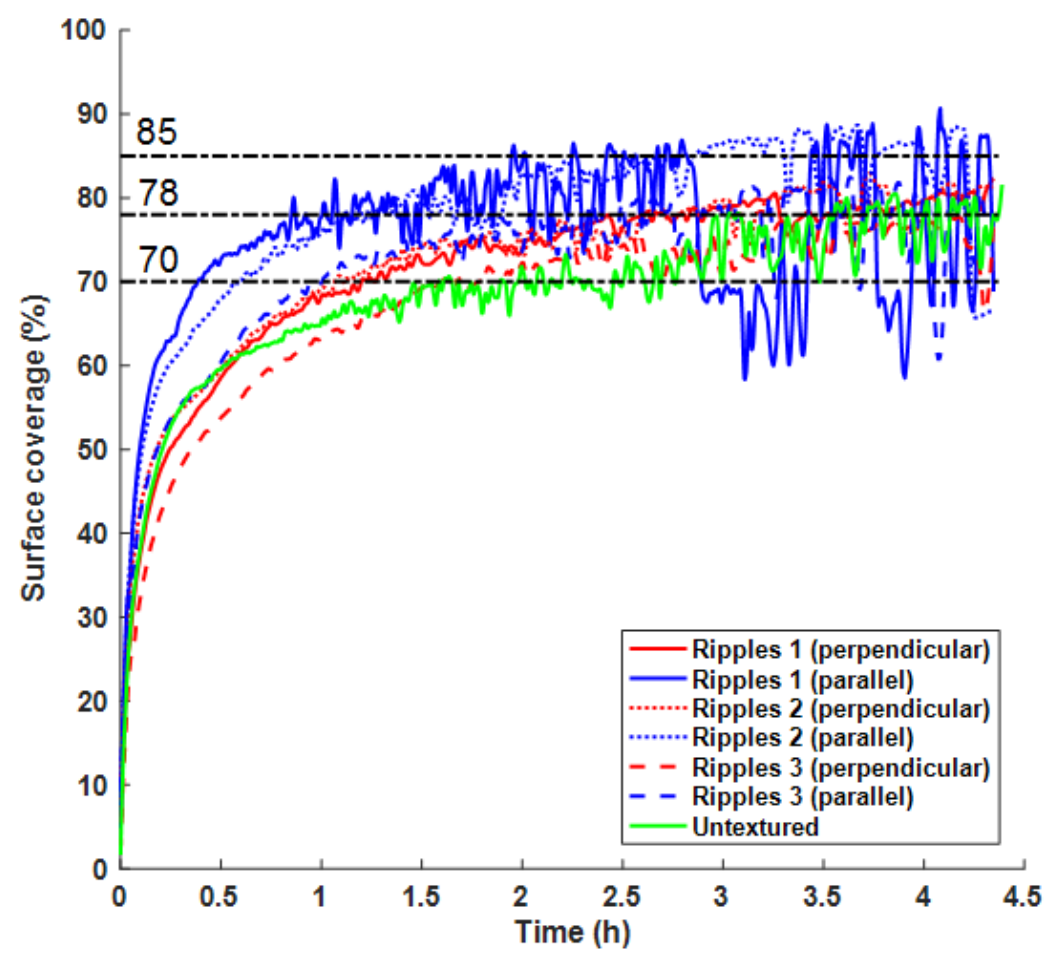

Figure 6: Surface coverage as a function of time. The studied ripple orientations are parallel and perpendicular to the direction of gravity.

\subsection{Impact of ripples on breath figure dynamics}

The breath figure dynamics of the three different textured surfaces with parallel and perpendicular orientation relative to the direction of gravity were compared to an untextured surface. The dynamics of condensation were characterized by the evolution of the number of droplets and the mean droplet radius $<\mathrm{R}>$ as a function of time $[16,20,43]$.

\subsubsection{Impact of ripples on the number of droplets}

The number of droplets as a function of time is shown figure 7 , where the curves illustrate four distinct steps. Each curve given in figures 7 and 8, presents an error around 400 seconds due to a transition between two data processing programs [29]. An overlapping of the two programs in this region has been carried out to help better readers understand.

- Step 1: Droplet appearance. In this step, droplets nucleation occurred and they grew to be visibly detectable. Prior to this stage, the droplets sizes were below the detection threshold of the experimental setup. This 
step was characterized by an important increase of the number of droplets which progressively covered the surface.

- Step 2: Droplet growth without coalescence. Droplet growth occurred at this point exclusively by incorporation of water vapor present in the air. The number of droplets remained constant.

- Step 3: Droplet growth with coalescence events. This step marked the point when coalescence between droplets began, decreasing the number of droplets.

- Step 4: Number of droplets stabilizes. If the surface is cooled, the number of droplets present as a result of coalescence will equal the number of newly formed droplets [16]. By coalescing, large droplets leave free spaces where new droplets can form. This stage marks the point when an equilibrium is reached between the decreasing number of droplets due to coalescences and the increasing number of new droplets. In this study, we stopped tracking the droplets before this plateau was reached. In a previous experimental context, this took place between $10^{3}$ and $10^{4}$ seconds.

As depicted in figure 7, the number of droplets did not vary a great deal between the different surfaces. This indicated that the presence of ripples had no impact on the number of droplets.

The low variations shown in figure 7 , which could in theory be attributed to the presence of ripples, were not due to texturing but instead were a response to the different degrees of cooling among the samples. The different families of textured surfaces - with ripples both perpendicular and parallel to the direction of gravity, and the untextured surface - were not cooled in the same manner. Due to the different positioning necessary to vary orientation, the three families of samples had slightly different contact surfaces with regard to the cold aluminum soleplates. As a result, before the temperature could stabilize and become homogenized, these observed areas presented inhomogeneous cooling rates. These variations in surface temperature modified the initial number of droplets and the density of detected droplets during the droplet appearance step (Step 1). The low variations of the maximum number of droplets as a function of the ripples orientation was thus only dependent upon the different cooling properties of these two kinds of samples. The cooling was enhanced for the samples with ripples parallel to the direction of gravity than that for ripples with perpendicular positioning. This explains why the maximum number of droplets was high for the samples with parallel ripples and low for those with perpendicular ripples.

As the maximum number of droplets were in close proximity to each other and as the low number of observed variations between the surfaces were not relevant due to cooling inhomogeneity, we can conclude that the maximum droplet numbers corresponding to the different surfaces were similar. However, the high degree of droplet deformation in response to parallel ripples for samples 1 and 


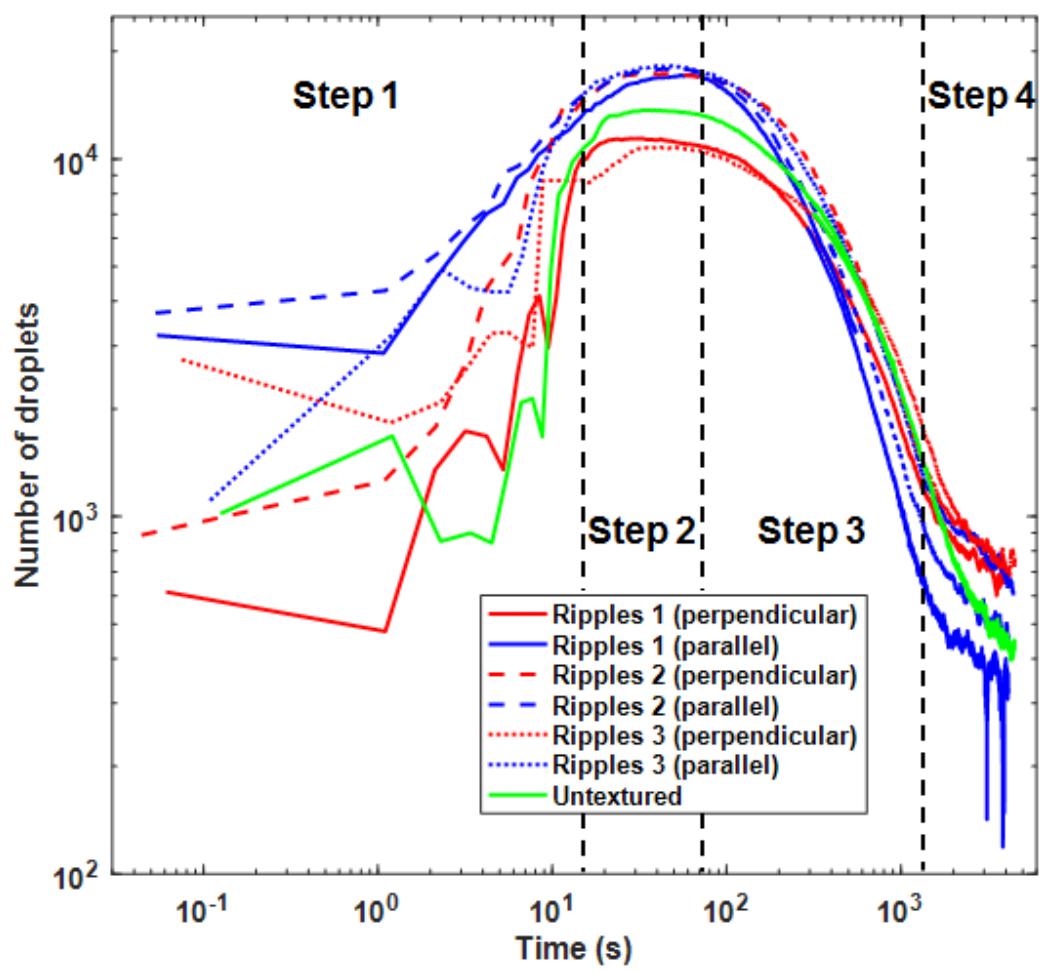

Figure 7: Number of droplets as a function of time for the different textured surfaces and for the untextured surface. The studied ripple orientations are parallel and perpendicular to the direction of gravity.

2 decreased the number of droplets between approximately $400 \mathrm{~s}$ and $4000 \mathrm{~s}$ (temperatures were homogeneous during this period). With the corresponding surface coverage being higher for these two textures, the free space made available by coalescence events was lower and therefore fewer droplets could appear. The total number of droplets, consequently, was lower.

\subsubsection{Droplet growth rate}

The droplets growth rate is described by the mean radius $<\mathrm{R}>$ of the total number of droplets as a function of time. The growth rate was characterized by four phases corresponding to the steps presented in the analysis of the number of droplets. The first phase was droplet appearance. During this short phase, the mean radius did not have the time to significantly increase. After which, the settled droplets grew by directly incorporating water vapor and followed the growth law: $<\mathrm{R}>\sim \mathrm{t}^{\mu}$ with $\mu=1 / 3[20]$. Once coalescence events started, droplet growth increased. The theoretical growth law at this point became: $\langle\mathrm{R}>\sim \mathrm{t}[20]$. The last phase is the mean droplet radius stagnation. Coalescence increased droplet radius and the appearance of new small droplets 
in the free spaces left by the coalescence events were in equilibrium and the mean radius remained constant [16].

The obtained mean droplet radius for the ripples surface 1 and the untextured sample is shown figure 8 . For visibility concerns, samples 2 and 3 are not represented in this diagram, which has no meaningful impact as their behaviors were analogous to those of sample 1.

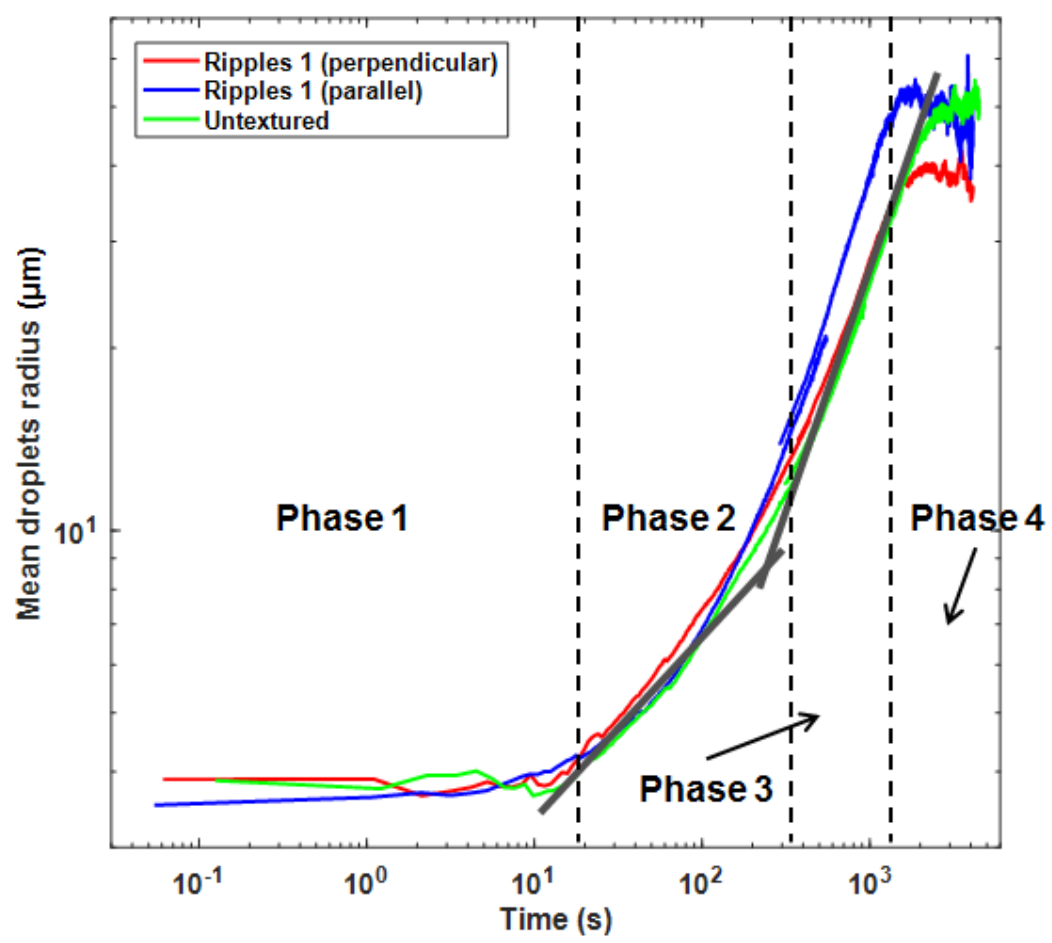

Figure 8: Mean droplet radius as a function of time for the different textured surfaces and for the untextured surface. The studied ripples orientations are parallel and perpendicular to the direction of gravity.

In figure 8 , black lines show respective growth rates with an exponent $\mu$ of 0.3 and 0.8. Droplet growth on the different surfaces corresponds to these same lines and no remarkable variation appeared between the types of surfaces. The droplet growth rates are in accordance with the theory characterized by initial growth with the exponent $\mu=1 / 3$ (growth without coalescence) and a second with the exponent $\mu$ about 1 . In the literature, an exponent between 0.75 and 1.03 is considered as following the law with coalescence: $<\mathrm{R}>\sim \mathrm{t}$ $[44,45,42,15]$.

Even if the dynamics did not depend on the presence of ripples, the value of the mean radius was impacted by the surface texture. As with the number of droplets, the curve of the parallel ripples for sample 1 did not follow the curves 
for the other samples at the end of the condensation experiments. Between approximately $300 \mathrm{~s}$ and $2000 \mathrm{~s}$, the mean radius of the parallel ripples for sample 1 was higher than it was for the other curves. This can be explained by the deformation of the droplets increasing their contact area with the surface and thus their radius. Moreover, as seen with the number of droplets, the new droplets nucleating in the freed spaces were fewer. The droplets distribution contained more big coalesced droplets than small newly nucleated droplets, what still increased the mean radius. This increase of the mean droplet radius also occurred with the parallel ripples on sample 2 , but in a less accentuated manner than for the parallel ripples on sample 1 .

\section{Conclusion}

We have presented in this article new results on the effect of orientation and height of submicrometric texturing on breath figures orientation and relaxation.

Experiments were made on a home-made apparatus. Submicrometric texturing was obtained by replication of LIPPS on polycarbonate surface, resulting in ripples structures with preferential directions [27, 28, 31]. The set of results shows that the presence of these ripples creates anisotropic droplet behavior. Droplets thus orient in the ripples direction. This orientation and the corresponding droplet deformation are dependent upon the height of the ripples; greater ripples height causes higher droplet deformation, characterized by higher droplet hysteresis.

Condensation tests were conducted on a vertical soleplate to favor droplet sliding. Using this configuration showed that the orientation of ripples has an impact on the geometry of droplets. When ripples are oriented in the direction of gravity, the amplitude of droplet deformation increases as droplet relaxation is significantly inhibited after coalescence occurs. Indeed, the droplets maintain a specific shape depending on the position and the size of the coalesced droplets.

While the presence of ripples impacts droplet shape, condensation dynamics (droplet growth by water vapor incorporation, droplet coalescence, ) are barely affected. We observed the same evolution of droplet numbers and mean droplet radius for the textured and untextured surfaces. A slight difference, however, occurred for higher ripples oriented in the direction of gravity (samples 1 and 2 ). This led us to conclude that when coalescence occurred with large droplets, droplet deformation decreases the number of droplets while increasing mean radius. Consequently, deformed droplets occupy more space, leaving less space for new droplets to appear on a given surface.

These results broaden the scope of the numerous studies made on the effect of periodic anisotropic surface pattern $[2,3,4,5]$. Indeed, most of investigations were made on sessile drops, which differs from the study of a dense pack of droplets (breath figure) $[15,16,17,18,46,47,48]$. Considering breath figures, this presented research shows that sub-micrometric pattern can affect breath figure geometry. This is very important for physical anti-fogging treatments of transparent surfaces. Indeed, literature mostly interested in the effect of pattern wider or of the same size as droplets, which is strongly affected droplets geometry 
but also the substrate transparency $[49,50,51]$. To preserve as much as possible substrate transparency integrity, pattern needs to be sub-micrometric.

These promising results are the first step to develop a transparent and antifogging surface by texturing.

\section{Acknowledgements}

This work was done as part of the OpenLab VAT@Lyon of the Group PSA.

Funding: This work was supported by the Group PSA and the French Ministry of Research.

[1] C. Huh and S.G. Mason. Effects of surface roughness on wetting (theoretical). Journal of Colloid and Interface Science, 60(1):11 - 38, 1977.

[2] W. Choi, A. Tuteja, J. M. Mabry, R. E. Cohen, and G. H. McKinley. A modified cassiebaxter relationship to explain contact angle hysteresis and anisotropy on non-wetting textured surfaces. Journal of Colloid and Interface Science, 339(1):208 - 216, 2009.

[3] N.A. Malvadkar, M.J. Hancock, K. Sekeroglu, W..J. Dressick, and M.C. Demirel. An engineered anisotropic nanofilm with unidirectional wetting properties. Nature Materials, 9:1023-1028, 2010.

[4] E. Contraires, J. Teisseire, E. Søndergård, and E. Barthel. Wetting against the nap - how asperity inclination determines unidirectional spreading. Soft Matter, 28:6067-6072, 2016.

[5] C.W. Extrand. Retention forces of a liquid slug in a rough capillary tube with symmetric or asymmetric features. Langmuir, 23(4):1867-1871, 2007. PMID: 17279668.

[6] M.K. Chaudhury, A. Chakrabarti, and S. Daniel. Generation of motion of drops with interfacial contact. Langmuir, 31(34):9266-9281, 2015. PMID: 25683896.

[7] K. Sekeroglu, U. A. Gurkan, U. Demirci, and M. C. Demirel. Transport of a soft cargo on a nanoscale ratchet. Applied Physics Letters, 99, 2011.

[8] H.R. Holmes and K. F. Bhringer. Transport velocity of droplets on ratchet conveyors. Advances in Colloid and Interface Science, pages -, 2017.

[9] Y. Liang, L. Shu, W. Natsu, and F. He. Anisotropic wetting characteristics versus roughness on machined surfaces of hydrophilic and hydrophobic materials. Applied Surface Science, 331:41 - 49, 2015.

[10] Y. Zhong, A. M. Jacobi, and J. G. Georgiadis. Effects of surface chemistry and groove geometry on wetting characteristics and droplet motion of water condensate on surfaces with rectangular microgrooves. International Journal of Heat and Mass Transfer, 57(2):629 - 641, 2013. 
[11] N. T. Chamakos, G. Karapetsas, and A. G. Papathanasiou. How asymmetric surfaces induce directional droplet motion. Colloids and Surfaces A: Physicochemical and Engineering Aspects, 511(Supplement C):180 - 189, 2016.

[12] S. LeClear, J. LeClear, Abhijeet, K.-C. Park, and W. Choi. Drop impact on inclined superhydrophobic surfaces. Journal of Colloid and Interface Science, 461(Supplement C):114 - 121, 2016.

[13] L. Liu, A.M. Jacobi, and D. Chvedov. A surface embossing technique to create micro-grooves on an aluminum fin stock for drainage enhancement. Journal of Micromechanics and Microengineering, 19(3):035026, 2009.

[14] Z. Yoshimitsu, A. Nakajima, T. Watanabe, and K. Hashimoto. Effects of surface structure on the hydrophobicity and sliding behavior of water droplets. Langmuir, 18(15):5818-5822, 2002.

[15] T. S. Yu, J. Park, H. Lim, and K. S. Breuer. Fog deposition and accumulation on smooth and textured hydrophobic surfaces. Langmuir, 28(35):12771-12778, 2012. PMID: 22845789.

[16] A.M. Macner, S. Daniel, and P.H. Steen. Condensation on surface energy gradient shifts drop size distribution toward small drops. Langmuir, 30:17881798, January 2014.

[17] L. Vonna and H. Haidara. Morphology and stability of water condensation structures on a series of self-similar micropatterned substrates. Soft Matter, 9:765-771, 2013.

[18] R. Seco-Gudiña, J. Guadarrama-Cetina, and W. González-Viñas. Dynamics of water condensation over arrays of hydrophilic patches. The European Physical Journal Special Topics, 226(6):1189-1198, Apr 2017.

[19] M.-G. Medici, A. Mongruel, L. Royon, and D. Beysens. Edge effects on water droplet condensation. Phys. Rev. E, 90:062403, Dec 2014.

[20] D. Beysens. Dew nucleation and growth. C. R. Phys., 7(910):1082 - 1100, 2006.

[21] K.-C. Park, S. S. Chhatre, S. Srinivasan, R. E. Cohen, and G. H. McKinley. Optimal design of permeable fiber network structures for fog harvesting. Langmuir, 29(43):13269-13277, 2013. PMID: 23895249.

[22] K. O. Zamuruyev, H. K. Bardaweel, C. J. Carron, N. J. Kenyon, O. Brand, J.-P. Delplanque, and C. E. Davis. Continuous droplet removal upon dropwise condensation of humid air on a hydrophobic micropatterned surface. Langmuir, 30(33):10133-10142, 2014.

[23] V. S. Nikolayev, P. Sibille, and D. A. Beysens. Coherent light transmission by a dew pattern. Optics Communications, 150:263-269, 1998. 
[24] B. Cemek Cemek and Y. Demir. Testing of the condensation characteristics and light transmissions of different plastic film covering materials. Polymer Testing, 24(3):284 - 289, 2005.

[25] Y. Li, J. Zhang, S. Zhu, H. Dong, F. Jia, Z. Wang, Z. Sun, L. Zhang, Y. Li, $\mathrm{H}$. Li, W. Xu, and B. Yang. Biomimetic surfaces for high-performance optics. Advanced Materials, 21(46):4731-4734, 2009.

[26] T. Mouterde, G. Lehoucq, A. Checco, C. T. Black, A. Rahman, T. Midavaine, C. Clanet, and D. Quéré. Antifogging abilities of model nanotextures. Nature Materials, 16:658-663, 2017.

[27] O. Varlamova, F. Costache, J. Reif, and M. Bestehorn. Self-organized pattern formation upon femtosecond laser ablation by circularly polarized light. Applied Surface Science, 252(13):4702 - 4706, 2006. Proceedings of the European Materials Research society 2005 - Symposium-J: Advances in Laser and Lamp Processing of Functional Materials.

[28] J. Reif, C. Martens, S. Uhlig, M. Ratzke, O. Varlamova, S. Valette, and S. Benayoun. On large area lipss coverage by multiple pulses. Applied Surface Science, 336(Supplement C):249 - 254, 2015. E-MRS 2014 Spring Meeting. Symposium J. Laser Interaction with Advanced Materials: Fundamentals and Applications.

[29] N. Pionnier, S. Boroomandi Barati, E. Contraires, R. Berger, M. Guibert, S. Benayoun, and S. Valette. Design of an environment controlled dew tracking setup to emphasize the role of the relative humidity on breath figures dynamics. EPJ Techniques and Instrumentation, 5(1):2, Feb 2018.

[30] I. Saarikoski, M. Suvanto, and T. A. Pakkanen. Modification of polycarbonate surface properties by nano-, micro-, and hierarchical micronanostructuring. Applied Surface Science, 255(22):9000 - 9005, 2009.

[31] S. Hammouti, B. Beaugiraud, M. Salvia, C. Mauclair, A. Pascale-Hamri, S. Benayoun, and S. Valette. Elaboration of submicron structures on peek polymer by femtosecond laser. Applied Surface Science, 327:277 - 287, 2015.

[32] PALRAM. Chemical resistance of polycarbonate products, February 2015.

[33] J.Y. Chung, J.P. Youngblood, and C.M. Stafford. Anisotropic wetting on tunable micro-wrinkled surfaces. Soft Matter, 3:1163-1169, 2007.

[34] P. Li, J. Xie, and Z. Deng. Characterization of irregularly micro-structured surfaces related to their wetting properties. Applied Surface Science, 335:29 $-38,2015$.

[35] J. Park, H.-S. Han, Y.-C. Kim, J.-P. Ahn, M.-R. Ok, K. E. Lee, Lee J.-W., P.-R. Cha, H.-K. Seok, and H. Jeon. Direct and accurate measurement of size dependent wetting behaviors for sessile water droplets. Scientific Reports, 5(18150), 2015. 
[36] C. Andrieu, D. A. Beysens, V. S. Nikolayev, and Y. Pomeau. Coalescence of sessile drops. Journal of Fluid Mechanics, 453:427-438, 2002.

[37] R. Narhe, D. Beysens, and V. S. Nikolayev. Contact line dynamics in drop coalescence and spreading. Langmuir, 20(4):1213-1221, 2004. PMID: 15803699 .

[38] P. G. de Gennes. Wetting: statics and dynamics. Rev. Mod. Phys., 57:827863, Jul 1985.

[39] J. F. Joanny and P. G. de Gennes. A model for contact angle hysteresis. The Journal of Chemical Physics, 81(1):552-562, 1984.

[40] H. B. Eral, D. J. C. M. 't Mannetje, and J. M. Oh. Contact angle hysteresis: a review of fundamentals and applications. Colloid and Polymer Science, 291(2):247-260, 2013.

[41] B. White, A. Sarkar, and A.-M. Kietzig. Fog-harvesting inspired by the stenocara beetle-an analysis of drop collection and removal from biomimetic samples with wetting contrast. Appl. Surf. Sci., (284):826-836, 2013.

[42] D. Beysens, A. Steyer, P. P. Guenoun, D. Fritter, and C. M. Knobler. How does dew form? Phase Transitions, 31:219-246, 1991.

[43] J. Guadarrama-Cetina, R. D. Narhe, D. A. Beysens, and W. GonzálezViñas. Droplet pattern and condensation gradient around a humidity sink. Phys. Rev. E, 89:012402, Jan 2014.

[44] J.E. Castillo, J.A. Weibel, and S.V. Garimella. The effect of relative humidity on dropwise condensation dynamics. International Journal of Heat and Mass Transfer, 80(0):759 - 766, 2015.

[45] M. Sokuler, G. K. Auernhammer, C. J. Liu, E. Bonaccurso, and H-J. Butt. Dynamics of condensation and evaporation: Effect of inter-drop spacing. EPL (Europhysics Letters), 89(3):36004, 2010.

[46] C. Ma, S. Bai, X. Peng, and Y. Meng. Transient spreading of water droplet on laser micro-structured sic surfaces. Applied Surface Science, 311:789$792,2014$.

[47] D. Huerta-Murillo, A.I. Aguilar-Morales, S. Alamri, J.T. Cardoso, R. Jagdheesh, A.F. Lasagni, and J.L. Ocaa. Fabrication of multi-scale periodic surface structures on ti-6al-4v by direct laser writing and direct laser interference patterning for modified wettability applications. Optics and Lasers in Engineering, 98:134 - 142, 2017.

[48] C. Ma, S. Bai, X. Peng, and Y. Meng. Anisotropic wettability of laser micro-grooved sic surfaces. Applied Surface Science, 284:930 - 935, 2013. 
[49] P. Comanns, C. Effertz, F. Hischen, K. Staudt, W. Bhme, and W. Baumgartner. Moisture harvesting and water transport through specialized micro-structures on the integument of lizards. Beilstein Journal of Nanotechnology, 2:204-214, 2011.

[50] Y. Zheng, H. Bai, Z. Huang, X. Tian, F.-Q. Nie, Y. Zhao, J. Zhai, and L. Jiang. Direct water collection on wetted spider silk. Nature, 463:640643, 2010.

[51] J. Ju, H. Bai, Y.i Zheng, T. Zhao, R. Fang, and L. Jiang. A multi-structural and multi-functional integrated fog collection system in cactus. Nature Communications, 3, 2012. 


\section{Figure titles and table}

Figure 1: Schematic view of the experimental setup.

Figure 2: (a) AFM scan of ripples replicated at $75 \%$ on polycarbonate. (b) A corresponding height profile of the AFM scan presented in (a).

Figure 3: Plot of the contact angle hysteresis of the three textured samples - 1, 2 and 3 - and of the untextured surface.

Figure 4: Study of the deformation and orientation of the droplets of the three textured samples and of the untextured surface. This study corresponds to the analysis of pictures taken at the same time (about $1 \mathrm{~h} 26 \mathrm{~min}$ ). The figure is comprised of black and white images (with white droplets) and shows corresponding droplets roundness and orientation. The roundness and the orientation are defined in the text. The color blue shows results obtained for ripples with parallel orientation to gravity, and red shows results for ripples with perpendicular orientation to gravity.

Figure 5: Diagram showing droplet relaxation on samples textured with ripples and fixed on a vertical support. Two droplet orientations are represented on ripples positioned parallel and perpendicular to the direction of gravity. The black arrows represent the direction of free motion, the red crossed arrows represent the pinning direction of a triple line, and the red dot crossed arrow shows pinning direction where the movement can be allowed with the inclination of the support.

Figure 6: Surface coverage as a function of time. The studied ripple orientations are parallel and perpendicular to the direction of gravity.

Figure 7: Number of droplets as a function of time for the different textured surfaces and for the untextured surface. The studied ripple orientations are parallel and perpendicular to the direction of gravity.

Figure 8: Mean droplet radius as a function of time for the different textured surfaces and for the untextured surface. The studied ripples orientations are parallel and perpendicular to the direction of gravity. 


\begin{tabular}{|c|c|c|c|c|c|c|c|c|}
\hline & Sample & $\mathrm{S}_{\mathrm{q}}(\mathrm{nm})$ & $\mathrm{S}_{\mathrm{a}}(\mathrm{nm})$ & $\begin{array}{l}\text { Features } \\
\text { height (nm) }\end{array}$ & $\begin{array}{c}\text { Contact } \\
\text { angle } \theta\left({ }^{\circ}\right)\end{array}$ & $\begin{array}{l}\text { Advancing } \\
\text { angle } \theta_{\mathrm{a}}\left({ }^{\circ}\right)\end{array}$ & $\begin{array}{l}\text { Receding } \\
\text { angle } \theta_{r}\left({ }^{\circ}\right)\end{array}$ & $\begin{array}{c}\text { Hysteresis } \\
\Delta \theta\left({ }^{\circ}\right)\end{array}$ \\
\hline \multirow{3}{*}{ Parallel } & 1 & $68.5 \pm 6.6$ & $59.0 \pm 4.2$ & $154 \pm 19$ & $97 \pm 1$ & $98 \pm 2$ & $52 \pm 11$ & $46 \pm 13$ \\
\hline & 2 & $51.4 \pm 11.2$ & $42.0 \pm 8.4$ & $108 \pm 15$ & $98 \pm 2$ & $96 \pm 1$ & $52 \pm 5$ & $44 \pm 6$ \\
\hline & 3 & $44.1 \pm 11.8$ & $35.8 \pm 10.0$ & $70 \pm 14$ & $99 \pm 2$ & $102 \pm 2$ & $64 \pm 5$ & $38 \pm 6$ \\
\hline \multirow{4}{*}{ Perpendicular } & 1 & $68.5 \pm 6.6$ & $59.0 \pm 4.2$ & $154 \pm 19$ & $93 \pm 1$ & $101 \pm 5$ & $70 \pm 3$ & $31 \pm 7$ \\
\hline & 2 & $51.4 \pm 11.2$ & $42.0 \pm 8.4$ & $108 \pm 15$ & $98 \pm 1$ & $101 \pm 2$ & $68 \pm 2$ & $34 \pm 4$ \\
\hline & 3 & $44.1 \pm 11.8$ & $35.8 \pm 10.0$ & $70 \pm 14$ & $92 \pm 7$ & $93 \pm 2$ & $69 \pm 6$ & $25 \pm 8$ \\
\hline & Untextured & $7.3 \pm 2.1$ & $5.6 \pm 1.9$ & & $95 \pm 2$ & $101 \pm 2$ & $68 \pm 2$ & $33 \pm 4$ \\
\hline
\end{tabular}

Table 2: Table 1: Table of the surface parameters of the three textured samples - 1, 2 and 3 - and of the untextured surface.

\section{Appendix}



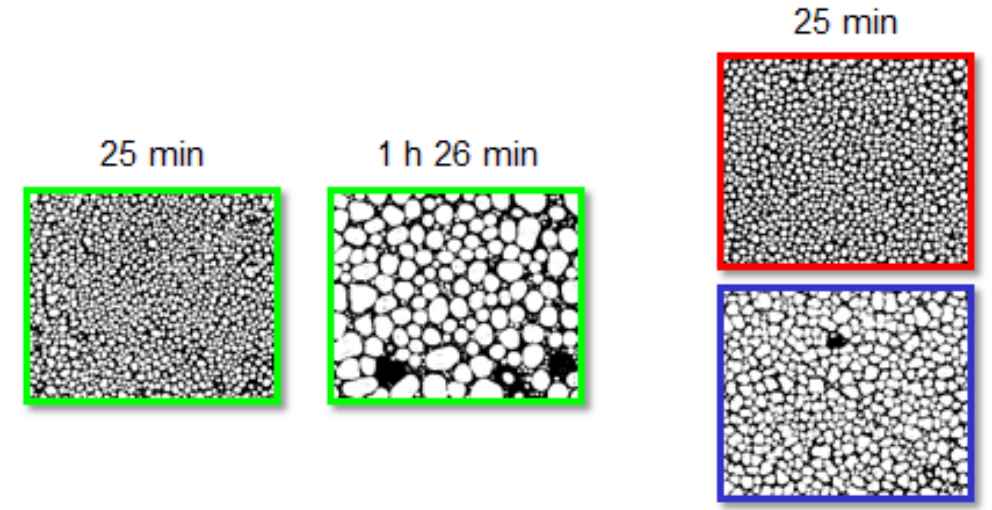

$1 \mathrm{~h} 26 \mathrm{~min}$
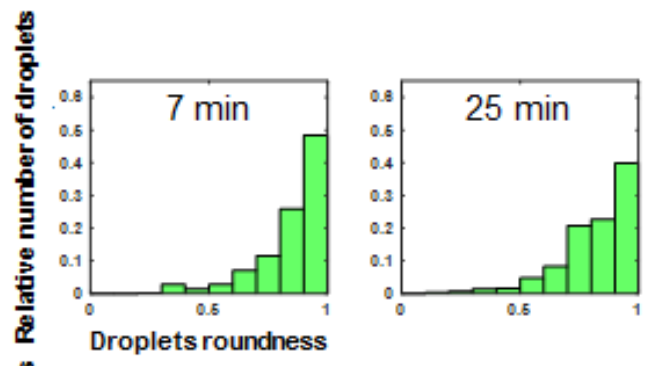

$25 \mathrm{~min}$

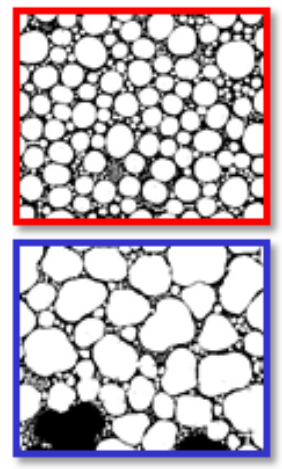

$1 \mathrm{~h} 26 \mathrm{~min}$
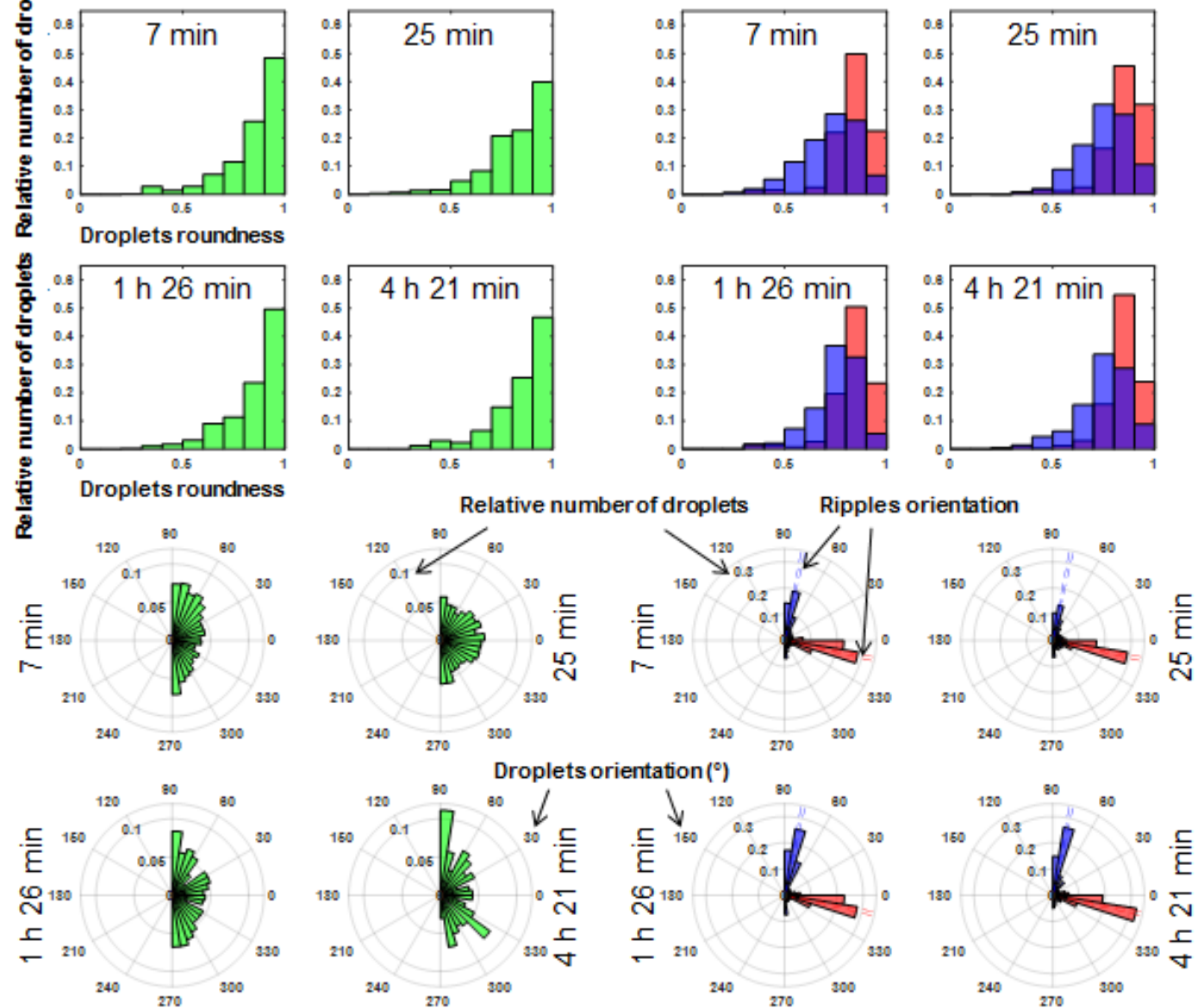

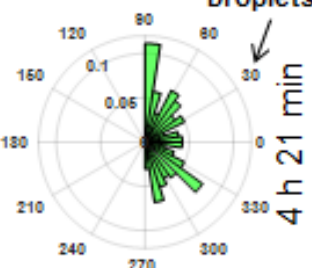

(a)

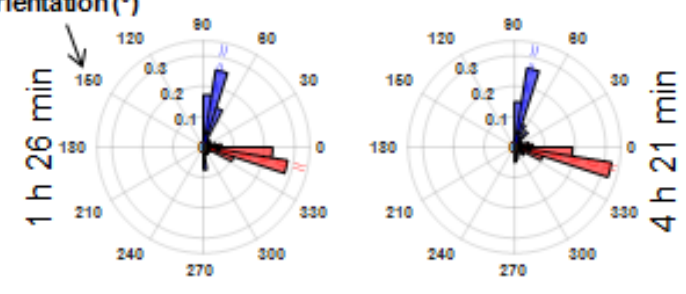

(b)

Figure 9: A time evolution study of the deformation and orientation of the droplets on an untextured surface and of sample 1 (highest ripple height). This study references analysis of pictures taken at different times. The figure is comprised of black and white images (with white droplets) and shows corresponding droplet roundness and orientation. The roundness and the orientation are defined in the text. Blue is used to show results obtained for ripples parallel to gravity, red shows results for with ripples perpendicular to gravity. 